\title{
Does platelet activity play a role in the pathogenesis of idiopathic ischemic priapism?
}

\author{
Yavuz Ufuk ${ }^{1}$, Yilmaz Hasan ${ }^{1}$, Ustuner Murat ${ }^{1}$, Ciftci Seyfettin ${ }^{1}$, Teke Kerem ${ }^{1}$, Culha Melih ${ }^{1}$ \\ ${ }^{1}$ Department of Urology, University of Kocaeli, Kocaeli, Turkey
}

\section{ABSTRACT}

Purpose: Mean platelet volume (MPV) is used to measure platelet size and is defined as a potential marker of platelet reactivity. Higher MPV levels have been defined as a risk factor for increased incidence of intravascular thrombosis and its associated diseases. We aimed to determine whether a relationship exists between the MPV and veno-occlusive component of idiopathic ischemic priapism (IIP).

Materials and methods: Between 2010 and 2014, 38 subjects were analyzed in two groups. One was composed of 15 patients with diagnosis as IIP in our institute, and the other contained 23 healthy control subjects. Complete blood count reports were retrospectively evaluated in both groups. MPV, platelet count (PLT), platelet distribution width (PDW), white blood cells (WBC), red blood cells (RBC), hemoglobin (Hb), reticulocyte distribution width (RDW) were measured in both groups.

Results: The mean ages were similar in IIP patients $(45.86 \pm 15.82)$ and control subjects (47.65 \pm 10.99$)$. The mean MPV values of IIP patients were significantly higher than control subjects $(\mathrm{p}<0.05)$. In contrast, also PLT counts were significantly lower in IIP patients, compared to control subjects $(p<0.05)$. The mean hemoglobin and WBC values were significantly lower in control group $(p<0.05)$. There was no significant difference of RBC, PDW and RDW values in both groups.

Conclusions: We found that the MPV was significantly higher in IIP patients compared to control subjects. The high MPV levels may have contributed to the veno-occlusive etiopathogenesis of IIP disease. We strongly suggest further prospective studies to recommend the use of MPV in routine practice.

\section{ARTICLE INFO}

\section{Key words:}

Priapism; Mean Platelet Volume;

Blood Platelets

Int Braz J Urol. 2016; 42: 118-22

Submitted for publication:

April 28, 2015

Accepted after revision:

August 11, 2015

\section{INTRODUCTION}

Idiopathic ischemic priapism (IIP) is an emergency condition including a persistent painful rigid erection that continues for longer than 4 hours and unrelieved by ejaculation or orgasm (1). Its incidence is about 1.5 per 100.000 person, and it is a sexual function-threatening andrological emergency (2). The underlying pathophysiology is still not clear. The condition is idiopathic in up to
$60 \%$ of cases but non-idiopathic pathologies commonly associated with hematologic abnormalities, particularly sickle cell disease, vasoactive intracavernosal injections, psychotropic medications, recreational drugs, and those secondary to malignancy may play a role (3).

Platelet volume indices (PVI) include mean platelet volume (MPV), platelet distribution with (PDW) and total platelet number and variation are indicative of change in platelet function (4). 
MPV is used to measure platelet size and its increase is associated to activation of platelets (5). Higher MPV levels are associated with the increase of other markers of platelet activity, including platelet aggregation, thromboxane synthesis, and expression of adhesion molecules (6). Therefore, it is demonstrated that elevated MPV is associated with ischemic pathologies such as unstable angina, myocardial infarction, ischemic stroke and venous thromboembolism $(5,7,8)$.

Because IIP is also an ischemic vascular disease, we aimed to determine whether a relationship exists between MPV and veno-occlusive component of IIP in this study.

\section{MATERIALS AND METHODS}

Between 2010 and 2014, 15 patients diagnosed with IIP in our institute were included in the study as study group. Control group was composed of 23 healthy subjects of similar ages. All patients and controls were Caucasian.

Patient's who complained of persistent rigid erection that continued longer than 4 hours and not relieving by ejaculation and orgasm, were diagnosed as priapism. After a detailed history and physical examination, cavernosal blood gas examinations and confirmatory penile doppler ultrasound were performed. A complete hematologic evaluation including peripheral blood smear was done. Pelvic magnetic resonance imaging (MRI) was performed in all IIP patients. In all patients, that was the first episode of priapism. However, three patients $(20 \%)$ complained of erection episodes without sexual stimulation that continued for 1-2 hours and terminated spontaneously in the last two years before the IIP episode.

None of the patients had any of the following diseases: systemic diseases (e.g. coronary artery disease, diabetes mellitus, hypertension), hematological disorders (sickle cell anemia, thrombotic thrombocytopenic purpura (TTP), idiopathic thrombocytopenic purpura (ITP), myeloproliferative disorders, leukemia, Bernard-Soulier syndrome, total number of platelets less than $150 \times 10^{3}$ / $\mu \mathrm{L}$ or more than $450 \times 10^{3} / \mu \mathrm{L}$, peripheral vascular diseases, splenectomy, active infectious disease, malignancy, renal or hepatic failure. None of the subjects were using anti-platelet or anticoagulant drugs, vasoactive intracavernosal injections, psychotropic medications, or recreational drugs.

Complete blood count, including hemoglobin $(\mathrm{Hb})$, mean corpuscular volume (MCV), white blood cell count (WBC), red blood cell count (RBC), platelet number (PLT), mean platelet volume (MPV), reticulocyte distribution width (RDW) and platelet distribution width (PDW) parameters were measured in both groups. Blood samples were drawn from the antecubital vein and they were collected in tubes containing dipotassium ethylenediaminetetraacetic acid. The parameters were measured by an automated blood counter (CELL-DYN ${ }^{\circledR}$ 3700, Abbott Laboratories).

All data were analyzed with Statistical Package for Social Science database program. The Independent Sample t test was used for continuous variables when variables were normally distributed and equal variations were assumed. The Mann-Whitney U test was used for categorical variables or for continuous variables when they were not distributed normally or equal variations were not assumed. Chi-square test was used to find the relationship between two independent categorical variables. A $p<0.05$ was considered significant in all statistics.

\section{RESULTS}

The mean ages were similar in IIP patients $(45.86 \pm 15.82)$ and control subjects (47.65 \pm 10.99$)$. The duration of rigid erection was $10.26 \pm 2.07$ in IIP patients. The penile artery flow was found minimal or absent in all IIP patients in the confirmatory penile doppler ultrasound examination. Peripheral blood smear results did not reveal any sign of hematologic disorders. The cavernosal blood gas measurements of IIP patients are shown in Table-1. Patient's had low $\mathrm{pH}$, low $\mathrm{pO}_{2}$ and high $\mathrm{pCO}_{2}$ in the cavernosal blood gas measurement. The comparison of complete blood count parameters between control subjects and IIP patients are shown in Table-2. The mean MPV values of IIP patients were significantly higher than control subjects $(\mathrm{p}<0.05)$. In contrast, the average number of platelets was significantly lower in IIP patients, compared to control subjects $(\mathrm{p}<0.05)$. The mean 
Table 1 - The cavernosal blood gas measurements of IIP patients.

\begin{tabular}{lcc}
\hline & & $M^{2} a{ } \pm \mathrm{Sd}^{*}$ \\
\hline Cavernosal blood gas & $\mathrm{pH}$ & $7.04 \pm 0.14$ \\
& $\mathrm{pO}_{2}$ & $23.71 \pm 4.34$ \\
& $\mathrm{pCO}_{2}$ & $77.64 \pm 10.2$ \\
\hline
\end{tabular}

$\mathbf{S d}^{*}=$ Standard deviation ted a relationship between MPV and varicocele. They concluded that high MPV values which is a marker of increased platelet activity may play an important role on the varicocele pathophysiology. They reported a correlation between the severity of varicocele and MPV (13). Similarly, Mahdavi-Zafarghandi et al. reported that MPV values with varicocele patients were higher than control group. They found a significant correlation

Table 2 - The comparison of complete blood count parameters between IIP patients and control subjects.

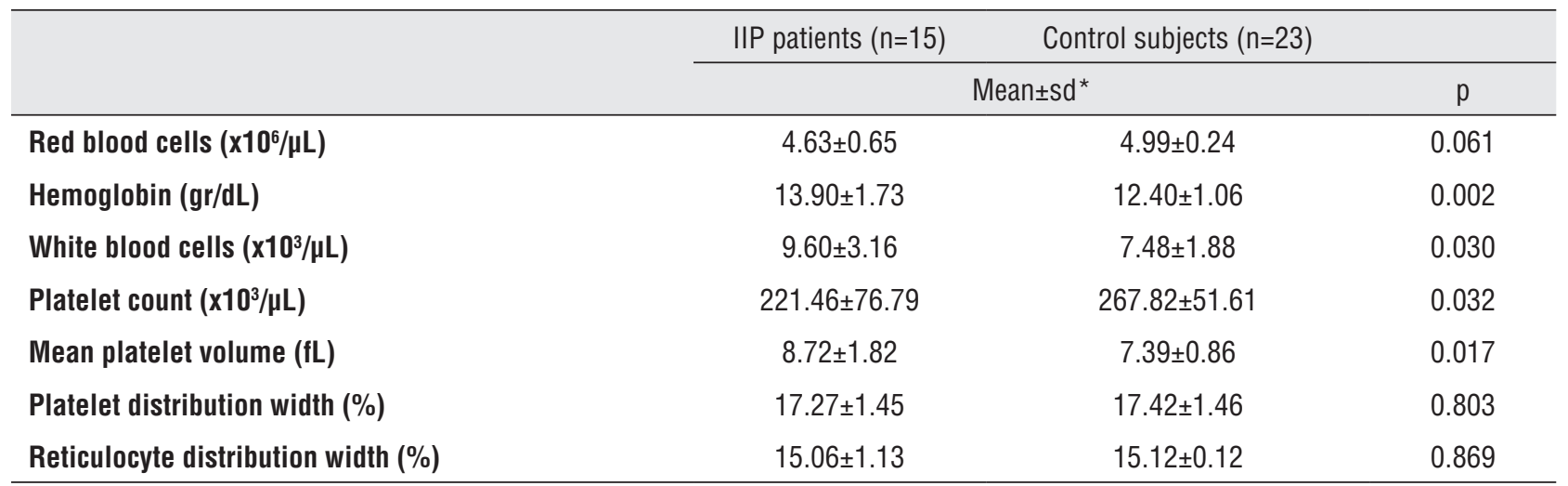

$\mathbf{S d}^{*}=$ Standard deviation

$\mathrm{Hb}$ values and the number of average WBCs were significantly lower in control group $(\mathrm{p}<0.05)$. There was no significant difference of RBC, PDW and RDW values in both groups.

\section{DISCUSSION}

Platelets are heterogeneous in size and density regarding their activity. Platelets with larger size are metabolically and enzymatically more active $(9,10)$ and have greater prothrombotic potential (6). Therefore, platelet volume has been assumed as a marker of platelet reactivity (11). MPV is a parameter of complete blood count that is commonly used to measure the average volume of platelets (12). It is the most validated and prominent platelet volume marker (4) and it can be assumed a potential marker of platelet reactivity (5).

MPV was evaluated for the pathogenesis of several urological diseases. Bozkurt et al. repor- with varicocele grade and the level of the MPV (12). Ciftci et al. also demonstrated that the MPV values were significantly higher in patients with vasculogenic erectile dysfunction and they suggested that high platelet activity and total platelet count play a role in the pathogenesis of vascular complications such as cavernosal arterial insufficiency in vasculogenic erectile dysfunction (14). On the other hand, several studies found a significant relationship between high MPV levels and ischemic stroke $(7,15,16)$. Additionally, Bilgic et al. found that elevated MPV was significantly associated with worse outcomes in acute mesenteric ischemia (17).

In the present study, we found significantly higher MPV levels in IIP patients compared to healthy controls. There are two hypotheses to explain the higher MPV levels in IIP patients. First, the MPV levels may be normal without priapism episodes just as control subjects and it acutely in- 
creases at the time of priapism episodes because of various inflammatory conditions or loss of platelets. It is already demonstrated that platelet production is regulated to preserve a constant total body platelet mass (18). The PDW is computed as the coefficient of variation of the average volume of the platelet population. A high PDW indicates that the platelets are more variable in volume than normal $(19,20)$ and it can be a sign of active platelet release (21). However, we found that the PDW levels were similar between IIP patients and control subjects. Besides that, total platelet count was significantly lower in IIP patients compared to control subjects. Platelets would be down regulated in IIP patients in order to maintain a constant total platelet mass because of higher MPV levels (larger platelets). These findings demonstrated that IIP patients regulated the MPV, PDW and total platelet count values in a chronically time period in order to maintain a constant total platelet mass.

Second, some people may have more active platelets with higher MPV levels and these people may have greater risk for episodes of priapism. Although the etiopathogenesis of IIP remains unclear, the pathophysiology of the condition includes venous outflow occlusion and the resultant cessation of cavernosal arterial inflow leading to hypoxia and micro vascular thrombosis of the corpora cavernosa (22). Upadhyay and colleagues examined the histology of the corpora cavernosa in patients with prolonged priapism. They revealed that an organized thrombus filling the cavernous sinuses caused venous obstruction, stasis and recurrent priapism (23). Probably, metabolically and enzymatically more active platelets with higher MPV levels leading to a tendency of thrombus formation in the cavernous sinuses may have contributed to the pathogenesis of IIP. Also, Braekkan et al. demonstrated that higher MPV levels were significantly associated with higher risk of venous thromboembolism pathogenesis (24). Addionally, higher MPV levels have been defined as a risk factor for increased incidence of intravascular thrombosis and its associated diseases $(7,8,14-17,24-27)$. Consequently, according to these findings, metabolically and enzymatically more active platelets with higher MPV levels may have contributed to the pathogenesis of IIP. Hence, higher levels of MPV and lower total platelet counts would be predictive for IIP in a risk based approach.

In the present study, WBC and hemoglobin concentrations were found significantly higher in IIP patients compared to control subjects. However, the mean levels of both parameters were ranged in normal spectrum. Acute inflammation would be a possible cause of the slightly increase of leucocytes. In addition, although hemoglobin concentration was higher, red blood cell counts were similar in both groups.

This study has some limitations. The number of IIP patients was relatively small in the present study. While evaluating the prothrombotic activity, other markers of platelet activity including beta-thromboglobulin, platelet factor IV and fibrinolytic status are lacking in the present study. For more insight on the hemodynamics in IIP, studies with large population and assessment of platelet activity with additional markers must be performed.

We found MPV values significantly higher in IIP patients compared to control subjects. The high MPV levels may have contributed to the veno-occlusive pathogenesis of IIP disease. We strongly suggest further prospective studies to recommend the use of MPV in routine practice.

\section{ABBREVATIONS}

IIP = Idiopathic ischemic priapism

MPV = Mean platelet volume

MRI = Magnetic resonance imaging

TTP = Thrombotic thrombocytopenic purpura

ITP = Idiopathic thrombocytopenic purpura

$\mathrm{Hb}=$ Hemoglobin

$\mathrm{MCV}=$ Mean corpuscular volume

WBC $=$ White blood cell

$\mathrm{RBC}=$ Red blood cell

PLT $=$ Platelet number

PDW = Platelet distribution width

RDW = Reticulocyte distribution width

\section{CONFLICT OF INTEREST}

None declared. 


\section{REFERENCES}

1. Pryor J, Akkus E, Alter G, Jordan G, Lebret T, Levine L, et al. Priapism. J Sex Med. 2004; 1:116-20.

2. Sedigh 0 , Rolle L, Negro CL, Ceruti C, Timpano M, Galletto $E$, et al. Early insertion of inflatable prosthesis for intractable ischemic priapism: our experience and review of the literature. Int J Impot Res. 2011; 23:158-64.

3. Ralph DJ, Garaffa G, Muneer A, Freeman A, Rees R, Christopher AN, et al. The immediate insertion of a penile prosthesis for acute ischaemic priapism. Eur Urol. 2009; 56:1033-8.

4. Leader A, Pereg D, Lishner M. Are platelet volume indices of clinical use? A multidisciplinary review. Ann Med. 2012; 44:805-16.

5. Chu SG, Becker RC, Berger PB, Bhatt DL, Eikelboom JW, Konkle $B$, et al. Mean platelet volume as a predictor of cardiovascular risk: a systematic review and meta-analysis. J Thromb Haemost. 2010; 8:148-56.

6. Kamath S, Blann AD, Lip GY. Platelet activation: assessment and quantification. Eur Heart J. 2001; 22:1561-71.

7. Arikanoglu A, Yucel Y, Acar A, Cevik MU, Akil E, Varol S. The relationship of the mean platelet volume and C-reactive protein levels with mortality in ischemic stroke patients. Eur Rev Med Pharmacol Sci. 2013; 17:1774-7.

8. Cil H, Yavuz C, Islamoglu Y, Tekbas EÖ, Demirtas S, Atilgan ZA, et al. Platelet count and mean platelet volume in patients with in-hospital deep venous thrombosis. Clin Appl Thromb Hemost. 2012; 18:650-3.

9. Martin JF, Trowbridge EA, Salmon G, Plumb J. The biological significance of platelet volume: its relationship to bleeding time, platelet thromboxane B2 production and megakaryocyte nuclear DNA concentration. Thromb Res. 1983; 32:443-60.

10. Thompson CB, Eaton KA, Princiotta SM, Rushin CA, Valeri CR. Size dependente platelet subpopulations: relationship of platelet volume to ultrastructure, enzymatic activity, and function. $\mathrm{Br} \mathrm{J}$ Haematol. 1982; 50:509-19.

11. Sansanayudh N, Anothaisintawee T, Muntham D, McEvoy M, Attia J, Thakkinstian A. Mean platelet volume and coronary artery disease: a systematic review and meta-analysis. Int J Cardiol. 2014; 175:433-40. Erratum in: Int J Cardiol. 2014; 177(3):1145. AmmarinThakkinstian [corrected to Thakkinstian, Ammarin].

12. Mahdavi-Zafarghandi R, Shakiba B, Keramati MR, Tavakkoli M. Platelet volume indices in patients with varicocele. Clin Exp Reprod Med. 2014; 41:92-5.

13. Bozkurt $Y$, Soylemez H, Sancaktutar AA, Islamoglu $Y$, Kar A, Penbegul N, et al. Relationship between mean platelet volume and varicocele: a preliminary study. Urology. 2012; 79:1048-51.

14. Ciftci H, Yeni E, Demir M, Yagmur I, Gümüş K, Celik H, et al. the mean platelet volume be a risk factor for vasculogenic erectile dysfunction? World J Mens Health. 2013; 31:215-9.
15. Bath P, Algert C, Chapman N, Neal B; PROGRESS Collaborative Group. Association of mean platelet volume with risk of stroke among 3134 individuals with history of cerebrovascular disease. Stroke. 2004; 35:622-6.

16. Mayda-Domaç F, Misirli H, Yilmaz M. Prognostic role of mean platelet volume and platelet count in ischemic and hemorrhagic stroke. J Stroke Cerebrovasc Dis. 2010; 19:66-72.

17. Bilgiç İC, Gelecek S, Ozmen MM, Kasapoglu B. The association of elevated mean platelet volume with the outcome of acute mesenteric ischemia. Blood Coagul Fibrinolysis. 2015; 26:727-30.

18. Kuter DJ. Milestones in understanding platelet production: a historical overview. Br J Haematol. 2014; 165:248-58.

19. Jackson SR, Carter JM. Platelet volume: laboratory measurement and clinical application. Blood Rev. 1993; 7:10413.

20. Vagdatli E, Gounari E, Lazaridou E, Katsibourlia E, Tsikopoulou F, Labrianou I. Platelet distribution width: a simple, practical and specific marker of activation of coagulation. Hippokratia. 2010; 14:28-32.

21. Karagoz BA, Bilgi 0, Demirci H, Alpaslan O, Erikci AA, Sayan 0, et al. Platelet count and platelet distrubition width increase in lung cancer patients. Anatol J Investig. 2009;3:32-4.

22. Kovac JR, Mak SK, Garcia MM, Lue TF. A pathophysiologybased approach to the management of early priapism. Asian J Androl. 2013; 15:20-6.

23. Upadhyay J, Shekarriz B, Dhabuwala CB. Penile implant for intractable priapism associated with sickle cell disease. Urology. 1998; 51:638-9.

24. Braekkan SK, Mathiesen EB, Njølstad I, Wilsgaard T, Størmer $\mathrm{J}$, Hansen JB. Mean platelet volume is a risk factor for venous thromboembolism: the Tromsø Study, Tromsø, Norway. J Thromb Haemost. 2010; 8:157-62.

25. Martin JF, Bath PM, Burr ML. Influence of platelet size on outcome after myocardial infarction. Lancet. 1991; 338:1409-11.

26. Endler G, Klimesch A, Sunder-Plassmann $H$, Schillinger $M$, Exner M, Mannhalter $\mathrm{C}$, et al. Mean platelet volume is an independent risk factor for myocardial infarction but not for coronary artery disease. Br J Haematol. 2002; 117:399-404.

27. Sahin A, Sahin M, Yüksel H, Türkcü FM, Cınar Y, Cingü AK, et al. The mean platelet volume in patients with retinal vein occlusion. J Ophthalmol. 2013; 2013:236371.

\footnotetext{
Correspondence address: Yavuz Ufuk, MD Department of Urology University of Kocaeli, Eski Istanbul Yolu 10. km Umuttepe Kocaeli, 41380, Turkey E-mail: drufukyavuz@gmail.com
} 